\title{
Caracterização morfológica de cultivares de bananeira micropropagadas em estádio juvenil
}

\author{
Morphological characterization of banana micropropagated cultivars in juvenile phase
}

\author{
Rafael Hansen Madail** Leila Aparecida Salles Pio ${ }^{\text {II }}$ Moacir Pasqual ${ }^{\text {II }}$ \\ Sebastião de Oliveira e Silva ${ }^{\text {III }}$
}

\begin{abstract}
O objetivo deste trabalho foi determinar descritores morfológicos que possibilitassem a caracterização de cultivares de bananeira provenientes de micropropagação ainda na fase juvenil. Foram utilizadas 12 cultivares de bananeira de diferentes grupos genômicos e graus de ploidia, que foram cultivadas in vitro e posteriormente aclimatizadas em casa de vegetação. Após o período de três meses, foram avaliadas características morfológicas quantitativas e caracteres descritivos das plantas. Com base nos resultados obtidos, foi possível separar todas as cultivares estudadas e elaborar uma chave analítica que permite a identificação dessas cultivares após o período de apenas três meses de aclimatização.
\end{abstract}

Palavras-chave: Musa sp., morfologia, chave analítica.

\section{ABSTRACT}

\begin{abstract}
The aim of this study was to determine morphological descriptors that could enable the characterization of banana cultivars from micropropagation process during the juvenile phase. Twelve cultivars from different genomic groups and with different ploidy levels were grown in vitro and acclimatized in greenhouse for three months. After this period, plants quantitative morphological and descriptive characteristics were evaluated. The results allowed ranking the cultivars and preparing an analytical key to identify these cultivars after the period of three months of acclimatization.
\end{abstract}

Key words: Musa sp., morphology, analytical key.
O melhoramento genético da bananeira atualmente tem como objetivo a obtenção de cultivares capazes de resistir a doenças, como as sigatokas e os nematóides, bem como apresentar características agronômicas de interesse, como o porte reduzido e frutos com melhores qualidades organolépticas. Os programas de melhoramento de espécies de interesse econômico lançam, com relativa frequência, cultivares que apresentam características desejáveis e que são resultado de longas e intensas pesquisas.

No entanto, é fundamental que exista a possibilidade de se proteger essas novas cultivares da apropriação genética indevida, sendo que o primeiro passo para se garantir legalmente essa proteção é a identificação de critérios estabelecidos, ou seja, descritores. Tradicionalmente, os melhoristas têm utilizado características morfológicas para registro e lançamento de novas variedades (MILACH, 1998).

A maioria dos descritores morfológicos utilizada para se determinar os genótipos de bananeira se baseia em características da planta adulta, muitas delas ligadas às estruturas reprodutivas, como número de pencas, número de frutos, número de dias da plantação à floração e comprimento do fruto (AMORIM et al., 2009; LESSA et al., 2008; SANTOS et al., 2006 ).

$\mathrm{O}$ aumento da bananicultura no Brasil tem exigido uma maior demanda por mudas dessas plantas

\footnotetext{
ISetor de Fisiologia Vegetal, Universidade Federal de Lavras (UFLA), 37200-000, Lavras, MG, Brasil. E-mail: rhmadail@yahoo.com.br. Autor para correspondência.

IDepartamento de Agricultura, UFLA, Lavras, MG, Brasil.

IIIEMBRAPA Mandioca e Fruticultura Tropical, Cruz das Almas, BA, Brasil.
} 
e a micropropagação tem se apresentado como uma excelente ferramenta para abastecer o mercado produtor com mudas de atestada procedência genética e qualidade fitossanitária (BRAGA et al., 2001). Contudo, é necessário um rígido controle sobre a fidelidade genética das mudas de bananeira, obtidas via propagação in vitro a serem destinadas aos campos de produção, evitando prejuízos aos produtores (NÓBREGA, 2006). STOVER (1987), ao trabalhar com uma grande população de mudas micropropagadas da variedade 'Grand Naine', encontrou até $25 \%$ de plantas variantes em sua população, sendo muitas dessas variações manifestadas de 5-6 meses após o plantio e outras somente próximas à floração. Nesse sentido, seria adequado que se avaliassem características nas plantas ainda jovens para poder determinar as cultivares e certificá-las com segurança.

Com base no exposto, o objetivo deste trabalho foi avaliar características morfológicas de cultivares de bananeira que pudessem ser utilizadas como descritores desses materiais ainda na fase juvenil.

$\mathrm{O}$ experimento foi conduzido no Departamento de Agricultura da Universidade Federal de Lavras. Foram utilizados explantes constituídos de ápices caulinares de 12 cultivares de bananeira de grupos genômicos e graus de ploidia diferentes (Tabela 1), provenientes da Embrapa Mandioca e Fruticultura Tropical. Os explantes foram cultivados in vitro, em meio MS (MURASHIGE \& SKOOG, 1962) e mantidos em sala de crescimento com intensidade luminosa de $36 \mu \mathrm{Mol} \mathrm{m}^{-2} \mathrm{~s}^{-1}$, com fotoperíodo de 16 horas e temperatura de $25 \pm 2^{\circ} \mathrm{C}$. O material foi multiplicado em meio MS por duas gerações, cada uma com duração de 30 dias. Posteriormente, as plantas foram transferidas para estufa e acondicionadas em vasos plásticos de 0,5L com substrato constituído de uma parte de terra, uma parte de areia e uma parte de esterco, sendo mantidas sob regime de nebulização intermitente e sombreamento de $50 \%$. Semanalmente, foram realizadas regas com meio MS 50\% líquido sem açúcar. Após 90 dias de aclimatização, de fevereiro a abril, foram realizadas avaliações das seguintes características morfológicas: a) altura das plantas (AP - $\mathrm{cm}$ ): realizada com fita métrica; b) perímetro do pseudocaule (PP- $\mathrm{mm}$ ): realizado com paquímetro digital na altura da inserção da folha mais basal; c) número de folhas (NF): número de folhas plenamente expandidas e não senescentes; d) comprimento do limbo foliar (CL - cm): medida com fita métrica; e) largura do limbo foliar (LL - cm): medida com fita métrica.

Além dessas características, ainda foram avaliados caracteres morfológicos descritivos como o aspecto geral da planta (esguias - entrenós longos; compactas - entrenós curtos) cor do pseudocaule, cor do limbo, cor da nervura central, cor da borda do limbo, orientação da folha, consistência da folha e presença de manchas no limbo.

Os dados medidos foram submetidos à análise de variância pelo programa Winstat para Excel e as médias comparadas pelo teste de Tukey a $1 \%$ de probabilidade.

Todos os dados avaliados apresentaram diferenças entre as cultivares, com exceção para o número de folhas (Tabela 1). De modo geral, algumas

Tabela 1 - Características morfológicas de 12 cultivares de bananeira provenientes do programa de melhoramento genético da Embrapa Mandioca e Fruticultura Tropical micropropagadas após três meses de aclimatização.

\begin{tabular}{lllllc}
\hline Genótipo e ploidia & \multicolumn{1}{c}{$\mathrm{AP}$} & $\mathrm{CL}$ & $\mathrm{LL}$ & $\mathrm{PP}$ & $\mathrm{NF}$ \\
\hline Malbut (AA) & $26,4 \mathrm{ABC}$ & $26,33 \mathrm{AB}$ & $10,35 \mathrm{AB}$ & $13,69 \mathrm{AB}$ & $4,2 \mathrm{~A}$ \\
NBA (AA) & $17,2 \mathrm{E}$ & $19,97 \mathrm{BCD}$ & $9,11 \mathrm{ABC}$ & $13,13 \mathrm{~B}$ & $5,0 \mathrm{~A}$ \\
Caipira (AAA) & $25,2 \mathrm{ABCD}$ & $30,08 \mathrm{~A}$ & $11,5 \mathrm{~A}$ & $14,94 \mathrm{AB}$ & $4,8 \mathrm{~A}$ \\
Thap Maeo (AAB) & $28,6 \mathrm{~A}$ & $24,44 \mathrm{ABC}$ & $9,94 \mathrm{ABC}$ & $15,26 \mathrm{AB}$ & $4,8 \mathrm{~A}$ \\
Prata Anã (AAB) & $20,8 \mathrm{BCDE}$ & $22,44 \mathrm{BCD}$ & $11,17 \mathrm{~A}$ & $18,35 \mathrm{~A}$ & $5,2 \mathrm{~A}$ \\
Maçã (AAB) & $17,4 \mathrm{E}$ & $18,3 \mathrm{CD}$ & $7,09 \mathrm{C}$ & $14,27 \mathrm{AB}$ & $5,0 \mathrm{~A}$ \\
FHIA-02 (AAAA) & $16,2 \mathrm{E}$ & $18,92 \mathrm{CD}$ & $8,87 \mathrm{ABC}$ & $17,72 \mathrm{AB}$ & $5,4 \mathrm{~A}$ \\
Bucanero (AAAA) & $15,6 \mathrm{E}$ & $17,59 \mathrm{D}$ & $7,81 \mathrm{BC}$ & $16,97 \mathrm{AB}$ & $5,2 \mathrm{~A}$ \\
Princesa (AAAB) & $27,6 \mathrm{AB}$ & $24,4 \mathrm{ABC}$ & $9,42 \mathrm{ABC}$ & $14,43 \mathrm{AB}$ & $4,6 \mathrm{~A}$ \\
Garantida (AAAB) & $19,6 \mathrm{CDE}$ & $17,95 \mathrm{CD}$ & $7,2 \mathrm{BC}$ & $14,71 \mathrm{AB}$ & $5,4 \mathrm{~A}$ \\
Tropical (AAAB) & $17,4 \mathrm{E}$ & $17,94 \mathrm{CD}$ & $7,53 \mathrm{BC}$ & $15,33 \mathrm{AB}$ & $5,0 \mathrm{~A}$ \\
PA42-44 (AABB) & $18 \mathrm{DE}$ & $17,59 \mathrm{D}$ & $8,51 \mathrm{ABC}$ & $17,1 \mathrm{AB}$ & $6,0 \mathrm{~A}$ \\
CV(\%) & 14,46 & 12,24 & 14,08 & 12,88 & 16,57 \\
\hline
\end{tabular}

$\mathrm{AP}$ - altura da planta, CL - comprimento do limbo, LL - largura do limbo, PP - perímetro do pseudocaule, NF - número de folhas. Médias seguidas pela mesma letra dentro da coluna não diferem significativamente segundo o Teste de Tukey a $1 \%$ de probabilidade.

Ciência Rural, v.41, n.2, fev, 2011. 
cultivares, como 'Caipira', 'Thap Maeo', 'Princesa' e 'Malbut' se destacaram das demais em quase todas as características agronômicas avaliadas, apresentando maior altura de plantas e comprimento de folhas. No entanto, observou-se que não há uma relação dessas características com o grupo genômico e com a ploidia do material avaliado. Essa relação é esperada quando se avaliam materiais adultos, pois, em órgãos de crescimento altamente determinado, como flores e sementes, um maior conteúdo de DNA gera um aumento das células e, por conseguinte, aumento desses órgãos, o chamado efeito "gigas". Portanto, essa relação não era esperada nos resultados do presente trabalho.

Apenas a criteriosa avaliação dos parâmetros morfológicos para cada uma das cultivares possibilitou a caracterização delas. Como resultado prático, foi possível elaborar uma chave analítica dicotômica para diferenciação de todas as cultivares estudadas ainda em fase juvenil, após três meses de aclimatização. Elaborações de chaves analíticas para identificação de genótipos e variedades de plantas de amplo interesse comercial são raros, como, por exemplo, o trabalho de ALMEIDA et al. (1995) com cana-deaçúcar e de SEIFFERT (1984) com as espécies mais comuns de Bracchiaria, usadas em pastagens no país.

Chave para determinação dos genótipos:

1.Plantas esguias cujas folhas se inserem no pseudocaule distantes entre si

... 2

Plantas compactas cujas folhas se inserem no pseudocaule próximas entre si ........................................ 3

2.Plantas altas, em média maiores que $20 \mathrm{~cm}$................... 4

Plantas baixas, em média menores que $20 \mathrm{~cm}$................6

3.Pseudocaule e pecíolos verdes .......................................

Pseudocaule e pecíolos avermelhados ......PRATAANÃ

4.Folhas de grande comprimento - em torno de

$30 \mathrm{~cm}$..

Folhas em geral menores que $30 \mathrm{~cm}$................................ 9

5.Nervura central da mesma cor do limbo ...................... 7

Nervura central avermelhada ............................. PA42-44

6.Nervura central de coloração castanha .......TROPICAL

Nervura central da mesma coloração do limbo ......MAÇÃ

7.Folhas verde escuro opacas com manchas castanhas

abundantes

..BUCANERO

Folhas verde médio a verde escuro, manchas castanhas

pouco abundantes ou até mesmo ausentes.......FHIA 02

8.Nervura central de coloração castanha ...........THAP

MAEO

Nervura central da mesma coloração do limbo ..CAIPIRA

9.Borda do limbo vermelha .................................................

Borda do limbo castanha ...............................................

10.Apresenta manchas nas folhas ...................................11
Não apresenta manchas nas folhas PRINCESA 11.Nervura central predominantemente castanha ............ GARANTIDA

Nervura central verde nas folhas jovens e avermelhada nas folhas maduras MALBUT

Como conclusões, pode-se dizer que a avaliação das cultivares estudadas permitiu a caracterização destas com base em características morfológicas juvenis em plantas provenientes de micropropagação e aclimatizadas pelo período de três meses.

Foi obtida uma chave analítica dicotômica que possibilita identificar as cultivares desenvolvidas nas condições deste experimento antes de sua maturidade, assegurando a certificação do material aos produtores e aos programas de melhoramento em um tempo reduzido.

\section{REFERÊNCIAS}

ALMEIDA, M. et al. Chave-analítica para determinação de dez variedades de cana-de-açúcar (Saccharum spp.). Scientia Agricola, v.52, n.1, p.16-19, 1995. Disponível em: <http:// www.scielo.br/scielo.php? script=sci_arttext \& pid=S010390161995000100004>. Acesso em: 31 de ago. 2010. doi: 10.1590/S0103-90161995000100004.

AMORIM, E. P. et al. Variabilidade genética estimada entre diplóides de banana por meio de marcadores microssatélites. Pesquisa Agropecuária Brasileira, v.43, n.8, p. 1045-1052, 2008. Disponível em: <http://www.scielo.br/scielo.php?script=sci_arttext\&pid=S0100 $204 X 2008000800014 \& \operatorname{lng}=p t \& n r m=i s o \& t l n g=p t>$. Acesso em: 31 ago. 2010. doi: 10.1590/S0100-204X2008000800014.

BRAGA, M.F. et al. Avaliação de um protocolo para multiplicação in vitro de bananeira (Musa sp.) cv. Caipira (AAA). Revista Brasileira de Fruticultura, v.23, n.2, p. 215-219, 2001. Disponível em: <http://www.scielo.br/scielo.php?pid=S0100$29452001000200002 \&$ script $=$ sci_arttext $>$. Acesso em: 31 ago. 2010. doi: 10.1590/S0100-29452001000200002.

LESSA, L.S. et al. Avaliação agronômica de híbridos diplóides de bananeira. Ciência e Agrotecnologia, v.33, Edição Especial p. 1716-1721, 2009. Disponível em: <http:// www.scielo.br/scielo.php? script $=$ sci_arttext\&pid $=$ S1 413 70542009000700003>. Acesso em 31 ago. 2010. doi: 10.1590/ S1413-70542009000700003.

MILACH, S.C.K. Uso de marcadores moleculares na caracterização de cultivares. In: BORÉM, A. et al. (Ed). Biossegurança, proteção de cultivares, acesso aos recursos genéticos e propriedade industrial na agropecuária. Viçosa: UFV, 1998. p.43-58.

MURASHIGE T.; SKOOG, F. A revised medium for rapid growth and bioassays with tobacco tissue cultures. Physiologia Plantarum, v.15, n.3, p.473-497, 1962. 
NÓBREGA, J.P.R. Produção de mudas de bananeira (Musa spp. AAB) em função da poda e doses de nitrogênio e boro. 2006. 118f. Dissertação (Mestrado em Agronomia) Curso de Pós-graduação em Agronomia, Universidade Federal da Paraíba, PB.

SANTOS, S.C. et al. Caracterização morfológica e avaliação de cultivares de bananeira resistentes a Sigatoka negra (Mycosphaerella fijensis Morelet) no sudoeste goiano. Revista Brasileira de

Fruticultura, v.28, n.3, p.449-453, 2006. Disponível em: <http:/
/www.scielo.br/scielo.php?script=sci_arttext\&pid=S01002945 $2006000300024 \& \operatorname{lng}=$ pt\&nrm $=$ iso $\&$ t $\operatorname{lng}=p t>$. Acesso em: 31 ago. 2010. doi: 10.1590/S0100-29452006000300024.

SEIFFERT, N.F. Gramíneas forrageiras do gênero Bracchiaria. Campo Grande: EMBRAPA, 1984. 83p. (Circular interna, 1).

STOVER, R.H. Somaclonal variation in Grande Naine and Saba bananas in the nursery and field. In: PERSELEY G.J.; De LANGHE E.A. (Eds). Bananas and plantains breeding strategies. Canberra: ACIAR, 1987. p.136-139. 